\title{
Experimental Investigation of the Evaporator Section Tilted Angle and Filling Ratio on the Thermal Charateristics of a Two-phase Closed Thermosyphon
}

\author{
Aminc Goldoust ${ }^{1}$, Mohammad R. Sarmasti Emami ${ }^{*}$, Ali A. Ranjbar ${ }^{1}$ \\ ${ }^{1}$ Department of Mechanical Engineering, Babol University of Technology, Babol 4714871167, Iran \\ ${ }^{2}$ Department of Chemical Engineering, University of Science and Technology of Mazandaran, Behshahr 4851878195, Iran
}

Corresponding Author Email: m_r_emami@mazust.ac.ir

https://doi.org/10.18280/ijht.370226

Received: 24 April 2018

Accepted: 10 June 2019

\section{Keywords:}

two-phase closed thermosyphon, tilted angle, filling ratio, Rohsenow's correlation, thermal performance

\begin{abstract}
An experimental study was conducted in order to investigate the effect of filling ratio (F.R) and tilted angle $(\Phi)$ of the evaporator section on the thermal efficiency in a two-phase closed thermosyphon (TS) with the vertical condenser and adiabatic sections. Therefore, a copper tube with inner diameter of $14.5 \mathrm{~mm}$ was used with distilled water in the filling ratio $15 \%$ to $60 \%$ and input heat 100 to 250 watt. The evaporator section of TS (from the junction of an adiabatic section) is bent and compare with vertical positions. Through this study, it was found that optimum of F.R was $45 \%$ and the best-tilted angle for the evaporator was $60^{\circ}$ relative to the horizontal axis. Also, the boiling heat transfer coefficient rises about $15.2 \%$ when the evaporator section will be bent $60^{\circ}$ in optimized filling ratio. Furthermore, boiling heat transfer coefficient obtained from the experimental results of this research were compared with Rohsenow's correlation, who showed good agreement.
\end{abstract}

\section{INTRODUCTION}

The heat transfer is a section of engineering, and the always wishing energy efficiency provisions are driving engineers to continually improve the efficiency of heat transfer methods. The heat pipes are the best devices for heat transfer. The significant increase in heat pipe heat transfer, boiling and condensation of the two phenomena as well as the high-speed vapor of working fluid along the tube, is under vacuum conditions. The heat pipes without wicks, called two-phase closed thermosyphon (TS) [1-2]. As shown in Figure 1, TS, the working fluid within it, to get heat in the evaporator and then the loss of heat in the condenser, returns to the evaporator. The fluid in the TS, to return from the condenser to the evaporator, does not use a wick and do it with gravity. In this case, the evaporator should be lower than the position of the condenser in the direction of gravity ground [3].

TS performance is significantly affected by a large of parameters, such as geometry, the filling ratio of working fluid, properties of the working fluid, tilted angle, saturation conditions and etc. TS and other thermal devices for renewable energy applications such as in solar and geothermal can help you design more efficient, more cost-effective and greener systems [4]. Also, it can use for the electronic cooling system [5], heat transfer in permafrost regions [6].

Booddachan et al. [7], investigated the effect of tilted angles, aspect ratios and Bond number on the thermal performance of a TS. They obtained the tilted angle with highest thermal performance ranged from $60^{\circ}$ to $70^{\circ}$. Zuo et al. [8] studied the heat transfer of a tilted TS. They concluded that the minimum value of working fluid remains approximately constant from $20^{\circ}$ to $90^{\circ}$, with relative to the horizontal, and by decreasing the tilted angle increase considerably. Terdtoon et al. [9] studied the effects of F.R., A.R (Aspect Ratio) and TS position angle, different working fluids and different diameters of TSs.

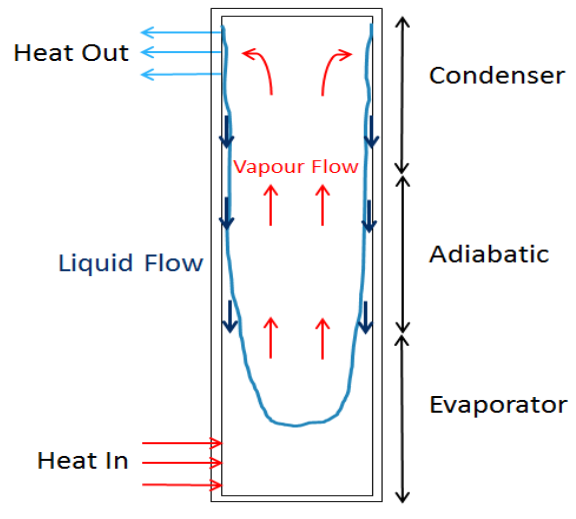

Figure 1. A schematic of a two-phased closed thermosyphon

TSs with tilted angle has better performance in the vertical position. It happens between $40^{\circ}$ to $70^{\circ}$. Ong and Haider-EAlahi [10] the effects of cooling flow rate and the filling ratio of R-134a on the thermal performance of a vertically tilted TS were also investigated experimentally. A.K. Mozumder et al [11] thermal performance of heat studied. Total heat transfer coefficient of the miniature heat pipe is found to be the higher for the Acetone as a pipe for various working fluids and filling ratios were working fluid. S.H. Noie et al. [12] were studied the effect of heat transfer rates, system pressure, aspect ratios and filling ratios on the heat transfer rate of a TS. The experimental results such as boiling and condensation heat transfer coefficients in TS were checked with the available correlations. M.R. Sarmasti Emami et al. [13] the effect of the aspect ratio and filling ratio on the thermal performance of a tilted TS has been studied experimentally. The best efficiency is in filling ratio of $45 \%$ and at a tilted angle of $60^{\circ}$ from horizontal. C.C. Hsu et al. [14] studied the effects of shock and vibration in the heat pipe with axis acceleration and tilted angle. 
They concluded that with increasing axis acceleration up to $1.5 \mathrm{~g}$ total thermal resistance increases of 5 to 30 percent. Recently, researchers have focused on optimizing the properties of nanofluids for use in heat transfer devices i.e. heat exchangers and heat pipes [15-17]. Kamyar et al. [18] examined the effects of nanofluids on the performance of TS. Results indicate that both nanofluids improve the proficiency through a reduction in thermal resistance by $65 \%$ (at $0.05 \%$ volume for $\mathrm{Al}_{2} \mathrm{O}_{3}$ ) and $57 \%$ (at $0.075 \%$ volume for $\mathrm{TiSiO}_{4}$ ).

As previous studies have shown, the effect of tilted angle of TS and heat pipes was studied. In this research, the effect of tilted angle of evaporator section and filling ratio on the thermal characteristics of a TS was investigated. In Figure 2, the tilted angles of evaporator section are shown.

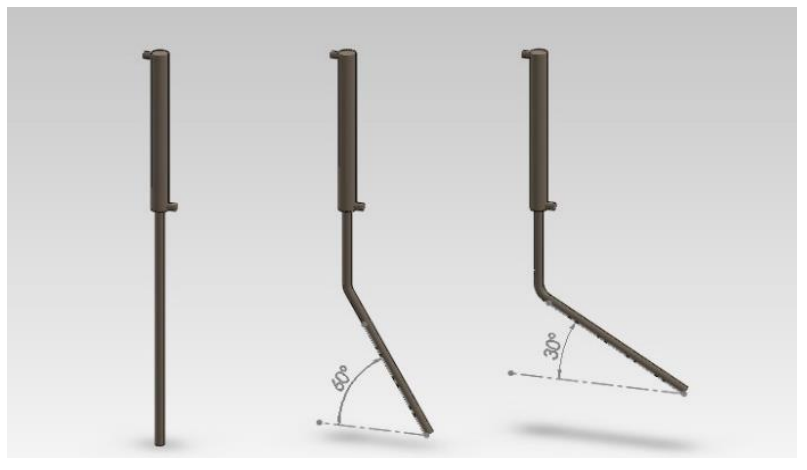

Figure 2. Tilted angle of evaporator section

\section{EXPRIMENTAL SETUP AND METHOD}

\subsection{Experimental setup}

In order to study the thermal efficiency of a two-phase closed thermosyphon, a specific experimental setup was designed and constructed. In this study, the tubes of copper were used with an internal diameter of $14.5 \mathrm{~mm}$ and the outer diameter of $16 \mathrm{~mm}$. View a summary of the design specifications for the TS in Table 1.

Table 1. Design summary of the TS

\begin{tabular}{|c|c|}
\hline Internal Diameter $\left(\mathrm{D}_{\mathrm{i}}\right)$ & 14.5 \\
\hline Outer Diameter $\left(\mathrm{D}_{\mathrm{o}}\right)$ & 16 \\
\hline Adiabatic Length $\left(\mathrm{L}_{\mathrm{a}}\right)$ & 200 \\
\hline Condenser Length $\left(\mathrm{L}_{\mathrm{c}}\right)$ & 400 \\
\hline Evaporator Length $\left(\mathrm{L}_{\mathrm{e}}\right)$ & 400 \\
\hline Aspect Ratio $\mathrm{Le}_{\mathrm{e}} / \mathrm{D}_{\mathrm{i}}(\mathrm{A}$ (R) & 28 \\
\hline
\end{tabular}

Distilled water was used as the working fluid, because it has good thermophysical properties, i.e. The heat of vaporization is high and in the range of 25 to $100{ }^{\circ} \mathrm{C}$ can be used [1]. Also, bending the evaporator section and the impact of changes the tilted angle on TS performance was evaluated. In this work the operating parameters studied were shown in Table 2.

Table 2. Operating parameter in this research

\begin{tabular}{|c|c|c|}
\hline $\begin{array}{c}\text { TS angle } \\
\text { (degree) }\end{array}$ & Input power (watt) & Filling ratio \\
\hline 90 & $100,150,200,250$ & $15 \%<$ F.R $<60 \%$ \\
\hline 60 & 200 & $15 \%<$ F.R $<60 \%$ \\
\hline 30 & 200 & $15 \%<$ F.R $<60 \%$ \\
\hline
\end{tabular}

The thermal characteristics of the TS were accomplished by distributing the temperature on the outer surface of the tube. Thermocouples were used by RTD PT100). The accuracy of thermocouples is \pm 0.1 Celsius.

To control the input power to the tubes of a rheostat device with a nominal power of $1000 \mathrm{~W}$ was used. Performance pressure determined with a pressure gauge that was connected to the top of the TS. The cooling water flow rate of a flow meter (Rotameter) was measured. As the rate of water entering the condenser was set to the temperature difference between the inlet and outlet reach to a level that was recognizable. Accordingly, the water flow rate of $250\left(\mathrm{~cm}^{3} / \mathrm{min}\right)$ was determined. The thermosyphon was vacuumed down to 10 (psi). Input power can also be adjusted so that $1000\left(\mathrm{~W} / \mathrm{m}^{2}\right)$ the heat flux was input to each TS. The tube with different diameters with a ratio of $15 \%, 30 \%, 45 \%$ and $60 \%$ was tested. A schematic of the experimental setup is shown in Figure 3.

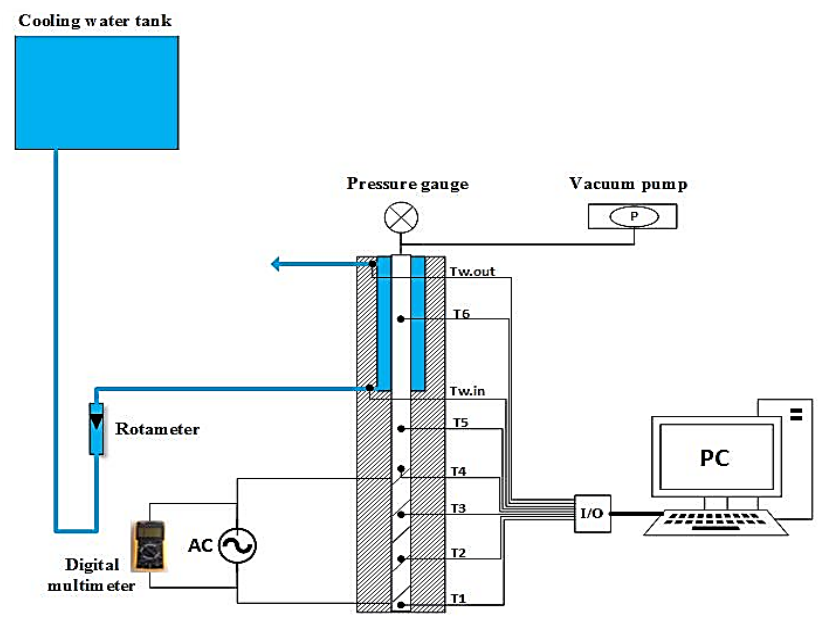

Figure 3. A schematic of the experimental setup

\subsection{Uncertainty analysis}

For the calculation of the uncertainty in the measured values of the tests using the manufacturer's specification for each device on the Table 3.

Table 3. Uncertainty in measured parameters

\begin{tabular}{|c|c|c|}
\hline Measurement & Device & $\begin{array}{c}\text { Relative } \\
\text { Uncertainty }\end{array}$ \\
\hline Temperature & $\begin{array}{c}\text { RTD(PT100) } \\
\text { thermocouple }\end{array}$ & $\pm 0.5^{\circ} \mathrm{C}$ \\
\hline $\begin{array}{c}\text { Cooling water } \\
\text { flow }\end{array}$ & Flow meter (Rotameter) & $\pm 5 \mathrm{ml}$ \\
\hline Voltage & $\begin{array}{c}\text { Best DT9205A } \\
\text { multimeter }\end{array}$ & $\pm 3.2 \%$ \\
\hline Current & $\begin{array}{c}\text { Best DT9205A } \\
\text { multimeter }\end{array}$ & $\pm 2.2 \%$ \\
\hline Electric resistance & $\begin{array}{c}\text { Best DT9205A } \\
\text { multimeter }\end{array}$ & $\pm 3.8 \%$ \\
\hline
\end{tabular}

By calculating the relative uncertainty of measurement values in Table 2 and putting in Eq. (1) was presented by Kline and McClintock [19] tests measure the amount of uncertainty is calculated:

$$
\Delta f=\sqrt{\sum_{i=1}^{i=n}\left(\frac{\partial f}{\partial x_{i}}\right) \Delta x_{i}}
$$


Consequently, the maximum value of uncertainty is for heat transfer coefficient about $4.06 \%$, the rate of output heat transfer about $3.2 \%$, input power about $3.8 \%$, and efficiency about $4.9 \%$.

\subsection{Heat transfer rate}

Input power and output heat, the most important value will be calculated on the basis of the results obtained. Using the following equation can be input voltage and electrical current, the actual power rate input in the evaporator section can be calculated by Eq. (2):

$$
\dot{Q}_{i n}=V . I-\dot{Q}_{\text {loss }}
$$

The rate of dissipated heat, as well as the following equation of heat dissipation through convection and radiation, can be obtained from Eq. (3):

$$
\dot{Q}_{\text {loss }}=\dot{Q}_{\text {rad. }}+\dot{Q}_{\text {conv. }}
$$

The rate of heat dissipated through radiation and convection around the tube insulation is calculated as Eqns. (4) and (5):

$$
\begin{aligned}
& \dot{Q}_{\text {rad. }}=\varepsilon . \sigma . A_{e}\left(T_{\text {ins. }}^{4}-T_{\text {air }}^{4}\right) \\
& \dot{Q}_{\text {conv. }}=h_{\text {conv. }} A_{e}\left(T_{\text {ins. }}-T_{\text {air }}\right)
\end{aligned}
$$

Heat transfer coefficient around the vertical and tilted cylinder is calculated from the relationship between Churchill and Chu [20] by Eq. (6), where Ra (Rayleigh number) of Eq. (7) is obtained:

$$
\begin{aligned}
& N u=\frac{h_{\text {conv. }} L_{e}}{k_{\text {air }}}=\left\{0.825+\frac{0387 R a^{1 / 6}}{\left[1+\left(\frac{0492}{\operatorname{Pr}}\right)^{9 / 16}\right]^{8 / 27}}\right\}^{2} \\
& R a=\frac{g \beta\left(T_{i n s}-T_{a i r}\right) L_{e}^{3}}{\alpha v}
\end{aligned}
$$

Incropera and De Witt noted that for $30<\Phi<90$, g can be replaced by gsin $\Phi$ in Eq. (7) can be used [21].

Heat transfer rate output from the Eq. (8) based on the difference in temperature around the condenser cooling water is obtained:

$$
\dot{Q}_{\text {out }}=\dot{m} c_{p, w}\left(T_{w, \text { out }}-T_{w, \text { in }}\right)
$$

\subsection{Evaporator heat transfer coefficient}

Experimental evaporation heat transfer coefficient was evaluated from the Eq. (9).

$$
h_{e}=\frac{\dot{Q}_{o u t}}{A_{e}\left(T_{v}-T_{e v a}\right)}
$$

where $\mathrm{T}_{\text {eva., }}$, The average temperature of evaporator surface and $\mathrm{T}_{\mathrm{v}}$ is vapor temperature that, in this research, was considered the adiabatic surface temperature based on older studies [2223].

It was found that nucleate boiling is the predominant mechanism in the evaporator section. Therefore, a correlation based on nucleate boiling were selected to compare with the experimental data obtained from this research. Rohsenow [24] correlated experimental data for nucleate pool boiling with Eq. (10):

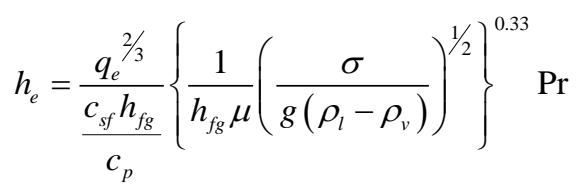

The values of the $C_{\text {sf }}$ are given in reference [25].

\section{RESULTS AND DISCUSSION}

A series of experiments were carried out to find the effect of varying parameters on the thermal characteristics of the two-phase closed thermosyphon.

\subsection{The temperature distribution}

The Figures 4 and 5 show the variation of the temperature along the length of the TS in the various tilted angles of evaporator section.

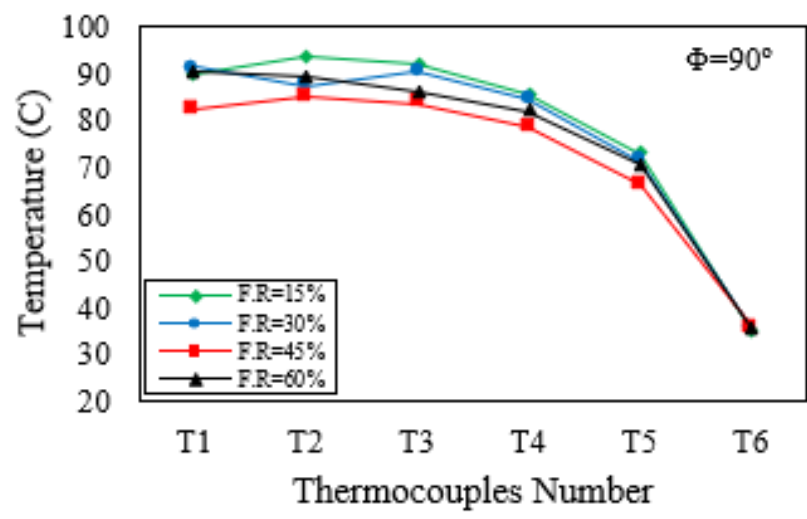

Figure 4. Variation of the temperature along the Ts with the $\Phi=90^{\circ}$ (vertical evaporator)

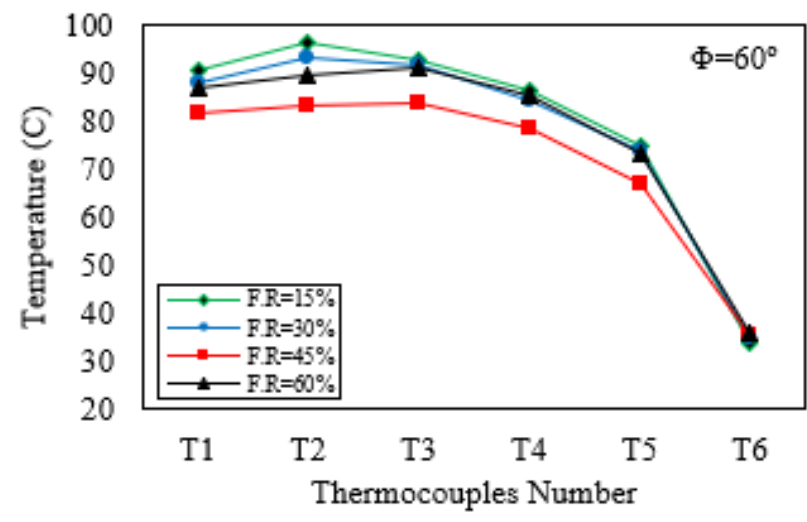

Figure 5. Variation of the temperature along the TS with the evaporator with $\Phi=60^{\circ}$ 
As can be seen in the above Figures 4 and 5, the evaporator surface temperature in the approximate shape remains constant. But in the adiabatic section, the temperature is reduced suddenly because of the input heat flux was not in this, the temperature difference between the evaporator and condenser is minimum in filling ratio of $45 \%$. Therefore the total thermal resistance is lowest in the pipe. The performance of the TS will be better at this filling ratio. Also, the reason for the rising temperature in the evaporator section at filling ratio of $15 \%$ can local drying of this section.

\subsection{Effect of filling ratio}

Change the amount of fluid in the TS is one of the very important factors affecting the performance of TS. Therefore, The filling ratio of fluid $15 \%, 30 \%, 45 \%$ and $60 \%$ were studied. Figure 6 shows the variation of efficiency $\left(\mathrm{Q}_{\text {out }} / \mathrm{Q}_{\text {in }}\right)$, by changing the filling ratio in the various tilted angles of the evaporator.

Which shows the highest efficiency for filling ratio will be off $45 \%$ and tilted angle of $60^{\circ}$. With an increasing filling ratio, due to the increased intensity of geyser boiling, efficiency is reduced. However, to increase the tilted angle to $60^{\circ}$ decreases the effect of this phenomenon [26].

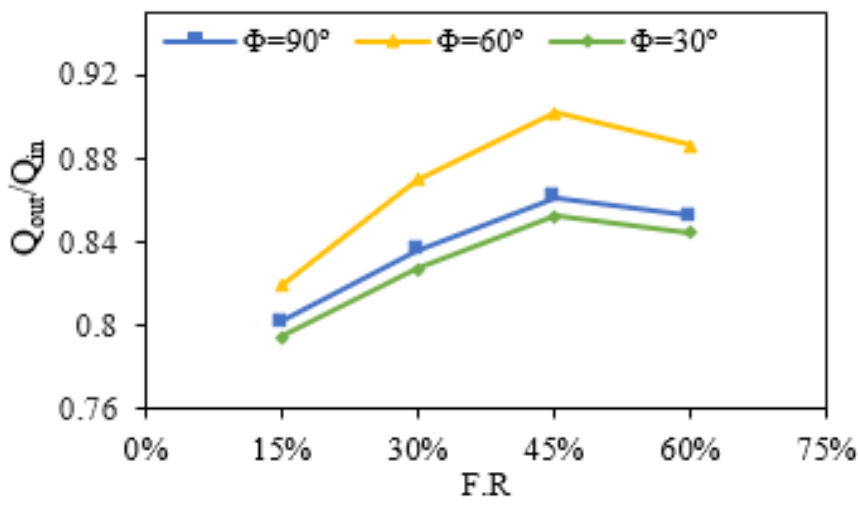

Figure 6. Variation of $\mathrm{Q}_{\text {out }} / \mathrm{Q}_{\text {in }}$ with the filling ratio for three tilted angles of evaporator

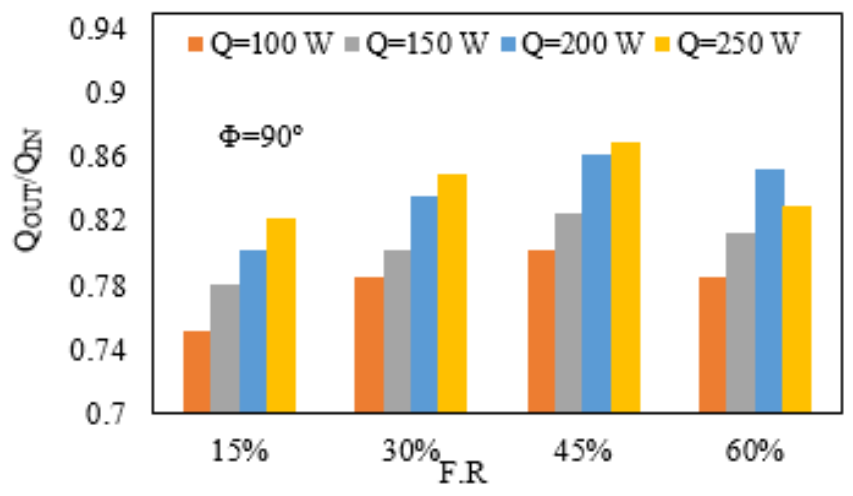

Figure 7. Variation of $\mathrm{Q}_{\text {out }} / \mathrm{Q}_{\text {in }}$ with the filling ratio for all input power for $\Phi=90^{\circ}$

Figure 7 shows the variation of the thermal efficiency $\left(\mathrm{Q}_{\text {out }} / \mathrm{Q}_{\text {in }}\right)$, respect to the filling ratio of the various input power.

It can be seen that the maximum thermal efficiency takes place in the F.R $=45 \%$ and $Q_{\text {in }}=250 \mathrm{~W}$ for $\Phi=90^{\circ}$. Also by increasing the filling ratio to $60 \%$ in $\mathrm{Q}_{\text {in }}=250 \mathrm{~W}$, the thermal efficiency of TS decreased. Because input power of $250 \mathrm{~W}$ is higher than the value of the boiling limits for this filling ratio and TS geometry [13].

\subsection{Effect of tilted angle of evaporator}

With bending the pipe of the evaporator and adiabatic junction, will be considered the tilted angle of the evaporator. Therefore, the effect of the tilted angle of the evaporator section at $90^{\circ}, 60^{\circ}$ and $30^{\circ}$ relative to the horizontal axis was investigated. The thermal efficiency for tilted angle relative to vertical TS in different F.R is shown in Figure 8.

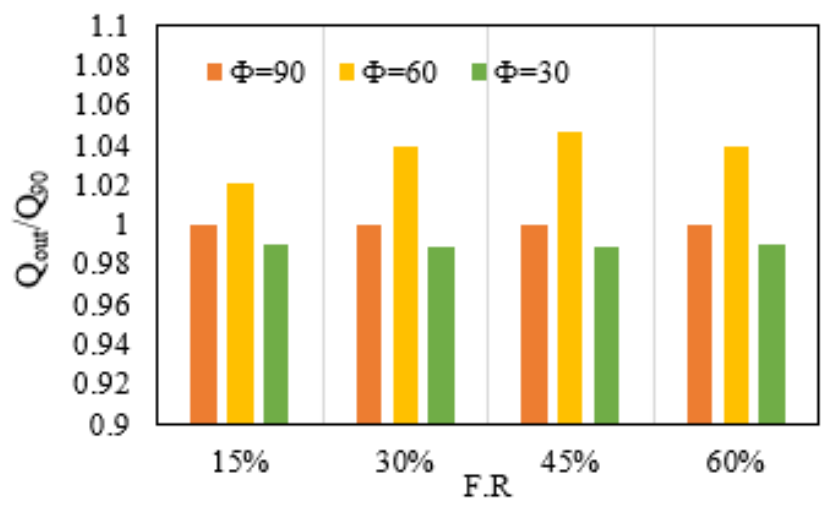

Figure 8. Variation of $\mathrm{Q}_{\text {out }} / \mathrm{Q}_{90}$ with the tilted angle

As shown in Figure 8, the maximum thermal efficiency of TS occurs at $60^{\circ}$ of a tilted angle and an optimum filling ratio (F.R. $=45 \%$ ).

Figure 9 shows that the evaporator heat transfer coefficient increased when the tilted angle of evaporator changed from vertical to $60^{\circ}$ and decreased when it bent to $30^{\circ}$.

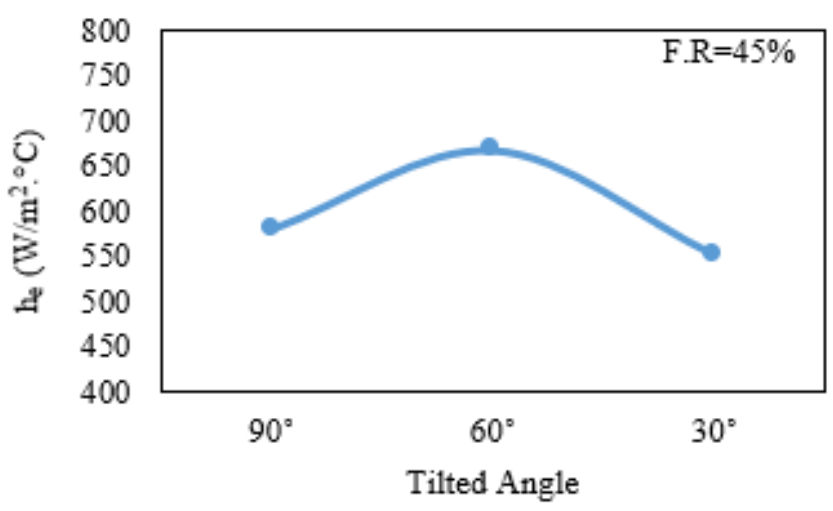

Figure 9. Variation of $h_{e}$ with the tilted angle for F.R $=45 \%$

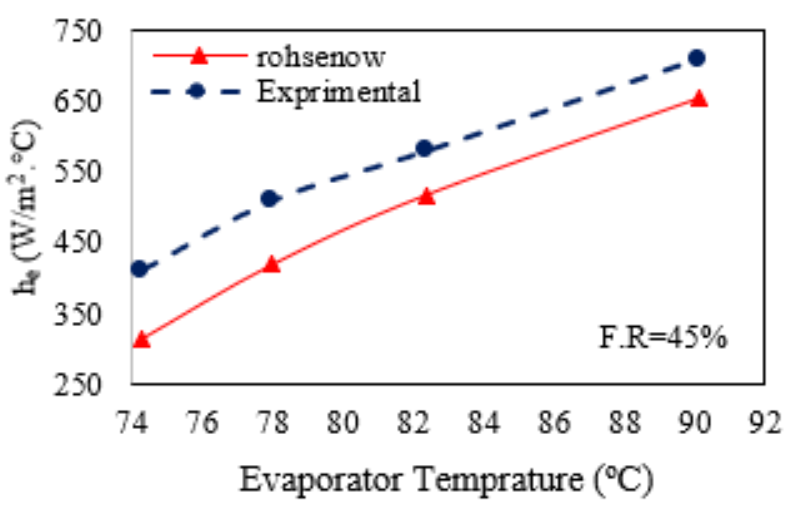

Figure 10. Comparison of boiling heat transfer coefficient with Rohsenow correlation [24] for F.R=45\% 
As explained earlier, the experimental results of this research can be compared with Rohsenow correlation in Eq. (10). As shown in Figure 10, a good agreement (around $15 \%$ on average) was observed between the results obtained from this study with Rohsenow correlation in the F.R. $=45 \%$.

\section{CONCLUSIONS}

In this research, the thermal characteristics of a two-phase closed thermosyphon (TS) with distilled water were studied experimentally. This investigation is mainly concerned with the effect of the evaporator section tilted angle at various filling ratio and input heat. The main results were as follows:

* The maximum thermal efficiency of TS occurs at F.R $=45 \%$ and $\Phi=60^{\circ}$ of evaporator section.

* The maximum output heat transfer rate for all filling ratios occurs at $60^{\circ}$.

* The geyser boiling phenomenon happened during the experiments for filling ratios greater than $45 \%$. Therefore, in this situation, the thermal efficiency of TS was reduced more quickly.

* The average temperature of the evaporator surface declined in optimum filling ratio and represents minimum total thermal resistance.

* Increasing the input heat will be caused by the increased the thermal efficiency, as long as it does not pass the boiling limited heat transfer.

* Application of various nanofluid as a working fluid and different geometry (i.e. length and diameter) of TS are recommendations for future studies in this situation.

\section{REFERENCES}

[1] Faghri, A. (2012). Review and advances in heat pipe science and technology. Journal of Heat Transfer, 134(12): http://doi.org/10.1115/1.4007407

[2] Noie, S.H., Sarmasti Emami, M.R., Khoshnoodi, M. (2007). Effect of inclination angle on thermal performance of a two-phase closed thermosyphon under normal operating condition. Heat Transf. Eng. 28(4): 365-371. https://doi.org/10.1080/01457630601122997

[3] Peterson, G.P. (1994). An introduction to Heat Pipe Modeling, Testing and Applications. John Wiley \& Sons, Hoboken, USA.

[4] Jafari, D., Franco, A., Filippeschi, S., Di Marco, P. (2016). Two-phase closed thermosyphons: A review of studies and solar applications. Renewable \& Sustainable Energy Reviews, 53: 575-593. http://doi.org/10.1016/j.rser.2015.09.002

[5] Gopi Kannan, K., Kamatchi, R., Venkatajalapathi, T., Krishnan, A.S. (2018). Enhanced heat transfer by thermosyphon method in electronic devices. Int. J. of Heat and Technology, 36(1): 339-343. https://doi.org/10.18280/ijht.360145

[6] Zhang, M., Lai, Y., Zhang, J., Sun, Z. (2011). Numerical study on cooling characteristics of two-phase closed thermosyphon embankment in permafrost regions. Cold Regions Science and Technology, 65(2): 203-210. https://doi.org/10.1016/j.coldregions.2010.08.001

[7] Booddacham, K., Tantakom, P., Terdtoon, P., Polchai, A. (1996). Thermal behavior of a HPDE thermosyphon.
Proc. of the 5th Int. Heat Pipe Symposium, Melbourne, Australia.

[8] Zuo, Z.J., Gunnerson, F.S. (1995). Heat transfer analysis of an tilted two-phase thermosyphon. Journal of Heat Transfer, 117

1073-1075. http://doi.org/10.1115/1.2836287

[9] Terdtoon, P., Ritthidech, S., Shiraishi, M. (1996). Effect of aspect ratio and bond number on heat transfer characteristics of an tilted two-phase closed thermosyphon at normal operating condition. Proceeding of the $5^{\text {th }}$ Int. Heat Pipe Symp, Melbourne, Australia, pp. 261-266.

[10] Ong, K.S., Haider-E-Alahi, M. (2003). Performance of a R-134a filled thermosyphon. Applied Thermal Engineering, 23(18): 2373-2381. http://doi.org/10.1016/s1359-4311(03)00207-2

[11] Mozumder, A.K., Akon, A.F., Chowdhury M.S.H., Banik, S.C. (2010). Performance of heat pipe for different working fluids and fill ratios. J. of Mechanical Engineering, 41(2): 96-102. http://dx.doi.org/10.3329/jme.v41i2.7473

[12] Noie, S.H., Kalaei, M.H., Khoshnoodi, M. (2005). Exprimental investigation of boiling and condensation heat transfer of a two phase closed thermosyphon. Int. J. of Eng. 18(1): 37-43.

[13] Sarmasti Emami, M.R., Noie, S.H., Khoshnoodi, M. (2008). Effect of aspect ratio and filling ratio on thermal performance of an tilted two-phase closed thermosyphon. Iranian Journal of Science and Technology Transaction B: Engineering, 32(B1): 39-51.

[14] Hsu, C.C., Chen, X.F., Yang, J.M. (2011). The effects of shock and vibration on heat pipe performance in reliability tests. $10^{\text {th }}$ Int. Heat Pipe Symp., Taipei, Taiwan, pp. 6-9.

[15] Esfe, H.M., Rostamian, H., Rejvani, M., Sarmasti Emami, M.R. (2018). Rheological behavior characteristics of $\mathrm{ZrO}_{2}-\mathrm{MWCNT} / 10 w 40$ hybrid nano-lubricant affected by temperature, concentration, and shear rate: An experimental study and a neural network simulating. Physica E: Low-dimensional Systems and Nanostructures, 102: 160-170. https://doi.org/10.1016/j.physe.2017.12.023

[16] Hemmat Esfe, M., Rahimi Raki, H., Sarmasti Emami, M.R., Afrand, M. (2019). Viscosity and rheological properties of antifreeze based nanofluid containing hybrid nano-powders of MWCNTs and $\mathrm{TiO}_{2}$ under different temperature conditions. Powder Technology, 342: 808-816. https://doi.org/10.1016/j.powtec.2018.10.032

[17] Hemmat Esfe, M., Sarmasti Emami, M.R., Kiannejad Amiri, M. (2019). Experimental investigation of effective parameters on MWCNT- $\mathrm{TiO}_{2} / \mathrm{SAE} 50$ hybrid nanofluid viscosity. Journal of Thermal Analysis and Calorimetry, in Press. https://doi.org/10.1007/s10973018-7986-0

[18] Kamyar, A., Ong, K.S., Saidur, R. (2013). Effects of nanofluids on heat transfer characteristics of a two-phase closed thermosyphon. International Journal of Heat and Mass Transfer, 65: 610-618. https://doi.org/10.1016/j.ijheatmasstransfer.2013.06.046

[19] Kline, S.J., McClintock, F.A. (1953). Describing uncertainties in single-sample experiments. Mech. Eng. 75(1): 3-8.

[20] Churchill, S.W., Chu, H.H.S. (1975). Correlating 
equations for laminar and turbulent free convection from a vertical plate. International Journal of Heat and Mass Transfer, 18(11):

1323-1329. https://doi.org/10.1016/0017-9310(75)90243-4

[21] Incropera, F.P., DeWitt, D.P. (2002). Introduction to Heat Transfer. 4th Edition, John Wiley \& Sons Australia, Chap.9.

[22] Huber, N., Bowman, W. (1996). Longitudinal vibration effects on a copper/water heat pipe's capillary limits. Journal of Thermophysics and Heat Transfer, 10(1): 9096. http://arc.aiaa.org/doi/10.2514/3.757

[23] Abou-Ziyan, H.Z., Helali, A., Fatouh, M., Abo El-Nasr, M.M. (2001). Performance of stationary and vibrated thermosyphon working with water and R134a. Applied Thermal Engineering, 21: 813-830. https://doi.org/10.1016/S1359-4311(00)00089-2

[24] Rohsenow, W.M. (1962). A method of correlating heat transfer data for surface boiling curves. Int. J. of Heat Transfer ASME, 84: 969-976. http://hdl.handle.net/1721.1/61431

[25] Pioro, I. (1998). Experimental evaluation of constants for the Rohsenow pool boiling correlation. International Journal of Heat and Mass Transfer, 42(11): 2003-2013. http://doi.org//10.1016/S0017-9310(98)00294-4

[26] Sarmasti Emami, M.R., Noie, S.H., Khoshnoodi, M., Hamed Mosavian, M.T., Kianifar, A. (2009). Investigation of geyser boiling phenomenon in a twophase closed thermosyphon. Heat Transfer Engineering, 30(5): 408-415. https://doi.org/10.1080/014576302414979

\section{NOMENCLATURE}

$\begin{array}{ll}A_{e} & \text { evaporator lateral surface, } \mathrm{m}^{2} \\ \text { A.R } & \text { aspect ratio } \\ c_{p, w} & \text { specific heat of water, } \mathrm{J} . \mathrm{kg}^{-1} \cdot{ }^{\circ} \mathrm{C}^{-1} \\ \mathrm{C}_{\mathrm{sf}} & \text { constant, determined from experimental data } \\ \mathrm{D}_{\mathrm{i}} & \text { internal diameter of pipe, } \mathrm{m} \\ \mathrm{D}_{\mathrm{o}} & \text { outlet diameter of pipe, } \mathrm{m} \\ \mathrm{F} . \mathrm{R} & \text { filling ratio }\left(=\mathrm{V}_{\mathrm{l}} / \mathrm{V} \mathrm{e}\right) \\ \mathrm{g} & \text { gravitational acceleration, } \mathrm{m} . \mathrm{s}^{-2} \\ \mathrm{~h}_{\text {cov. }} & \text { convection heat transfer coefficient, } \mathrm{W} \cdot \mathrm{m}^{-2} .{ }^{\circ} \mathrm{C}^{-1}\end{array}$

$\mathrm{h}_{\mathrm{e}} \quad$ heat transfer coefficient at evaporator, $\mathrm{W} \cdot \mathrm{m}^{-2} \cdot{ }^{\circ} \mathrm{C}^{-1}$

$\mathrm{h}_{\mathrm{fg}} \quad$ latent heat of vaporization, J.kg-1

I current, $\mathrm{A}$

$\mathrm{k}_{\text {air }} \quad$ thermal conductivity of air, $\mathrm{W} \cdot \mathrm{m}^{-1} \cdot{ }^{\circ} \mathrm{C}^{-1}$

$\mathrm{k}_{\mathrm{l}} \quad$ thermal conductivity of liquid, $\mathrm{W} \cdot \mathrm{m}^{-} \cdot{ }^{\circ} \mathrm{C}^{-1}$

$\mathrm{L}_{\mathrm{c}} \quad$ condenser length, $\mathrm{m}$

$\mathrm{L}_{\mathrm{e}} \quad$ evaporator length, $\mathrm{m}$

$\dot{m} \quad$ mass flow rate of water, $\mathrm{kg} . \mathrm{s}^{-1}$

$\mathrm{Nu} \quad$ Nusselt number $\left(=\mathrm{h}_{\text {conv. }} \mathrm{L}_{\mathrm{e}} / \mathrm{k}_{\text {air }}\right)$

Pr Prandtl number $(=v / \alpha)$

$\mathrm{q}_{\mathrm{e}} \quad$ input heat flux, W. $\mathrm{m}^{-2}$

$\mathrm{Q}_{\text {in }} \quad$ input heat into the evaporator section, W

$\mathrm{Q}_{\text {cov }}$ convection heat transfer rate, W

Qloss heat loss by radiation and convection, W

Qout transmitted heat from the condenser section, W

$\mathrm{Q}_{\text {rad. }} \quad$ radiation heat transfer rate, $\mathrm{W}$

$\mathrm{P}_{\mathrm{atm}} \quad$ standard atmospheric pressure, $\mathrm{Pa}$

$\mathrm{P}_{\text {sat }} \quad$ vapor saturation pressure, $\mathrm{Pa}$

$\mathrm{Ra} \quad$ Rayleigh number $\left(=g \beta\left(T_{\text {ins }}-T_{\text {air }}\right) L_{e}^{3} / \alpha v\right)$

$\mathrm{T}_{\text {air }} \quad$ air temperature, ${ }^{\circ} \mathrm{C}$

$\mathrm{T}_{\text {eva }} \quad$ average temperature of evaporator section, ${ }^{\circ} \mathrm{C}$

$\mathrm{T}_{\text {ins }} \quad$ temperature on external surface of insulation, ${ }^{\circ} \mathrm{C}$

$\mathrm{T}_{\mathrm{w} . i n} \quad$ inlet water temperature of condenser, ${ }^{\circ} \mathrm{C}$

$\mathrm{T}_{\mathrm{w} . \mathrm{o}} \quad$ outlet water temperature of condenser, ${ }^{\circ} \mathrm{C}$

$\mathrm{T}_{\mathrm{v}} \quad$ vapor temperature, ${ }^{\circ} \mathrm{C}$

$\mathrm{V}$ voltage, $\mathrm{V}$

$\mathrm{V}_{\mathrm{e}} \quad$ evaporator volume, $\mathrm{m}^{3}$

$\mathrm{V}_{1} \quad$ liquid volume, $\mathrm{m}^{3}$

\section{Greek symbols}

$\alpha \quad$ thermal diffusivity of air, $\mathrm{m}^{2} . \mathrm{s}^{-1},(=\mathrm{k} / \rho . \mathrm{cp})$

$\beta \quad$ inverse of film temperature of air, $\mathrm{K}^{-1},\left(=\frac{1}{T_{f}}\right)$

$v \quad$ kinematic viscosity of air, $\mathrm{m}^{2} \cdot \mathrm{s}^{-1},(=\mu / \rho)$

1 viscosity of liquid, $\mathrm{kg} \cdot \mathrm{m}^{-1} \mathrm{~s}^{-1}$

$\rho_{1} \quad$ density of liquid, $\mathrm{kg} \cdot \mathrm{m}^{-3}$

$\rho_{\mathrm{v}} \quad$ density of vapor, $\mathrm{kg} \cdot \mathrm{m}^{-3}$

$\sigma \quad$ Stefan Boltzmann constant in Eq.(4) $\left(\mathrm{W} / \mathrm{m}^{2} . \mathrm{K}^{4}\right)$

$\varepsilon \quad$ emissive factor of insulator

$\Phi \quad$ tilted angle (measured against horizontal) 